\title{
A Forecast of Industrial and Commercial Drinking Water Consumption in Hamburg
}

\author{
Johann Wackerbauer \\ Ifo Institute, München, Germany \\ Email: wackerbauer@ifo.de
}

How to cite this paper: Wackerbauer, J. (2017) A Forecast of Industrial and Commercial Drinking Water Consumption in Hamburg. Open Access Library Journal, 4: e3425.

https://doi.org/10.4236/oalib.1103425

Received: March 3, 2017

Accepted: April 14, 2017

Published: April 17, 2017

Copyright $\odot 2017$ by author and Open Access Library Inc.

This work is licensed under the Creative Commons Attribution International License (CC BY 4.0).

http://creativecommons.org/licenses/by/4.0/

\section{(c) (i) Open Access}

\begin{abstract}
This paper reports about a forecast of drinking water consumption in Hamburg up to the year 2045 which was done in co-operation of the Institute for Social-Ecological Research with the Ifo Institute. While the Institute for Social-Ecological Research was responsible for the drinking water demand of private households, the Ifo Institute undertook a long-term forecast of the industrial and commercial drinking water consumption. Comparable water demand forecasts for other cities or regions treat the industrial water consumption compared to domestic consumption rather rudimentary. The innovation of this forecast versus previous, conventional approaches is the choice of the workforce instead of the population as a reference point for the water requirements of enterprises. It is described in this paper how the problems of predicting industrial and commercial water consumption based on limited information were solved. Forecasts of sectoral employment were completed by determining the specific water needs for each sector and by assumptions about efficiency improvements in drinking water consumption. Those assumptions were secured through written and oral inquiries of major customers of the Hamburg Waterworks and experts from the water sector.
\end{abstract}

\section{Subject Areas}

Environmental Economics

\section{Keywords}

Forecast, Water Use, Industrial Water Consumption, Commercial Water Consumption, Specific Water Demand

\section{Introduction}

This paper reports about a study in behalf of Hamburg Water Ltd. which has been conducted in co-operation of the Institute for Social-Ecological Research 
with the Ifo Institute [1]. While the Institute for Social-Ecological Research made a forecast of the drinking water demand of private households by 2045 , the Ifo Institute was responsible for the long-term forecast of the industrial and commercial drinking water consumption. The aim of the study was the update of a water demand forecast up to 2030, which was created in 2007 [2].

The development of future water demand is of great importance for a water utility such as Hamburg Water Ltd. with respect to water resources as well as technical and financial management. At present, yearly water demand is relatively constant after three decades of significant decrease. Specific water demand in households, which considerably decreased in the past, is expected to go down at a slower rate. Decreasing specific household demand will be compensated by a slightly increasing number of inhabitants, increasing industrial and commercial demand as well as an increased supply to neighboring utilities. The water demand study presented in this article details valuable insights into the sectoral as well as spatial development of water demand.

The water consumption forecast for the utilities Hamburg Water Ltd. is an important instrument for sustainable strategic planning of corporate decisions. The results also provide the basis for the allocation of water rights. Hamburg Water Ltd. extracts drinking water both within the urban area as at other locations in the surrounding areas of the metropolis. Therefore, a forecast of the demand for drinking water is essential to estimate the future use of water rights [3].

Comparable water demand forecasts for other cities or regions treat the industrial water consumption compared to domestic consumption rather rudimentary. The innovation of this forecast versus previous, conventional approaches is the choice of the workforce instead of the population as a reference point for the water requirements of enterprises. This water consumption forecast is based on a forecast of the economic development in Hamburg and the determination of specific water consumption in the different economic sectors of the metropolis [4]. The fundamentals of analysis and prognosis are made up from the available dataset of secondary sources and from own surveys in the industrial and commercial sector as well as their evaluation in conjunction with some key assumptions [5].

\section{The Region under Investigation}

Hamburg, officially Free and Hanseatic City of Hamburg [6], is the second largest city in Germany. It covers an area of 755.3 square kilometers, of which $92 \%$ are land area and $8 \%$ are surface water. Its population is over 1.8 million people (31-12-2012) and the population density is 2409 inhabitants per square kilometer [7]. Situated on the river Elbe, Hamburg is an international transport hub. The size of the port is approximately 74 square kilometers, being the 3 rd largest port in Europe by cargo tonnage and even the second largest by TEU's [8] [9]. Hamburg is also a global service, media, logistics and industrial hub, and an important financial centre for centuries, and it is the seat of Germany's oldest 
stock exchange and the world's second oldest bank, Berenberg Bank. The official long name reflects its history as a member of the medieval Hanseatic League, as a free imperial city of the Holy Roman Empire, a city-state, and one of the 16 states of Germany [10].

The water supply in Hamburg was the first modern water supply and sewage system on the European continent. At that time, in the middle of the 19th century, only England had a powerful subterranean pipeline system in Europe [11]. Its origin was due to the Great Fire in the Old Town of Hamburg in 1842, which destroyed a third of the inner city. The completely inadequate fire water supply contributed significantly to the extent of the destruction. Therefore, in the same year the construction of effective fire-fighting water supply as well as an advanced water supply and sewerage system started gradually. The extensive construction work was completed in 1848. Until today, a powerful water management with 17 waterworks grew continuously. The water supply in Hamburg was from the beginning publicly operated and is managed by the public-law company Hamburg Water Ltd.

The supply area of Hamburg Water Ltd. covers the urban area of the Free and Hanseatic City of Hamburg as well as 30 municipalities in the surrounding area. Twenty of these surrounding communities are wholly or partly supplied by Hamburg Water, and a further ten individual districts are connected to the supply network. In addition, Hamburg Water supplies drinking water to six water supply companies, so-called redistributors. Around 2.06 million inhabitants are living in the entire supply area, $13 \%$ of which are outside the urban area of Hamburg [12].

\section{Economic Forecast for Hamburg}

To predict the future water consumption it was necessary to make assumptions about the economic development at Hamburg. Therefore, the first step in the water demand forecast was the prediction of the economic development at Hamburg up to the year 2045. While there is evidence from official sources for forecasting the population and number of households, qualified predictions must be used for estimating the economic development at Hamburg. For this purpose, a commonly accepted sectoral forecast of PROGNOS was used which dated up to the year 2035 [13]. As our task was to forecast industrial and commercial water use up to the year 2045, we extrapolated the results of the PROGNOS forecast by making plausible assumptions about the further economic development at Hamburg. This forecast refers to value added and employees in fourteen different sectors of the Hamburg economy.

Due to the ports the business location of Hamburg is strongly influenced by the sectors of transport, logistics, trade and tourism. According the PROGNOS Report of 2010 [13], the individual sectors of the economy have the following shares of the 1.1 million employees at Hamburg:

- Trade, transport and tourism: $28.8 \%$;

- Financing, leasing and business services: $28.3 \%$; 
- Public and private services: $28.0 \%$;

- Manufacturing industry: $11.3 \%$;

- Construction: $3.2 \%$;

- Agriculture, forestry and fisheries: $0.5 \%$.

For the period up to the year 2035 PROGNOS expected a job growth in the service sectors with a simultaneous loss of importance of the manufacturing industry and the agriculture, forestry and fisheries. Following the extrapolation the total number of jobs in Hamburg will increase to a maximum value of $1,137,400$ in 2026, decreasing afterwards to 1,080,900 until the year 2045. In industry, the number of jobs is continuously decreasing from 125,300 in 2011 to 107,100 in 2045 , in agriculture, forestry and fishery from 5200 to 3300 . On the contrary, in the financing, leasing and business services sector the number of jobs is increasing from 307,100 in 2011 up to 333,800 in 2026, declining afterwards smoothly to 318,500 in 2045 . A similar development is expected for the public and private services starting at 308,100 jobs in 2011, reaching its peak at 325,500 in 2029 and ending at 317,600 jobs in 2045 (Figure 1).

\section{Determining Specific Water Use}

The next step was to determine the specific water demand for each sector. This is of central importance for the water demand forecast. For calculating the specific sectoral water consumption there are in principle three possibilities: First, the use of specific water consumption values for Germany which can be obtained from matching the national accounts with national environmental accounting. Secondly, the use of appropriate regionalized values from the environmental accounting of the federal states and third using data from Hamburg Water Ltd. As it turned out that the first and the second possibility had different disadvantages, the specific water consumption in the different sectors was derived by matching

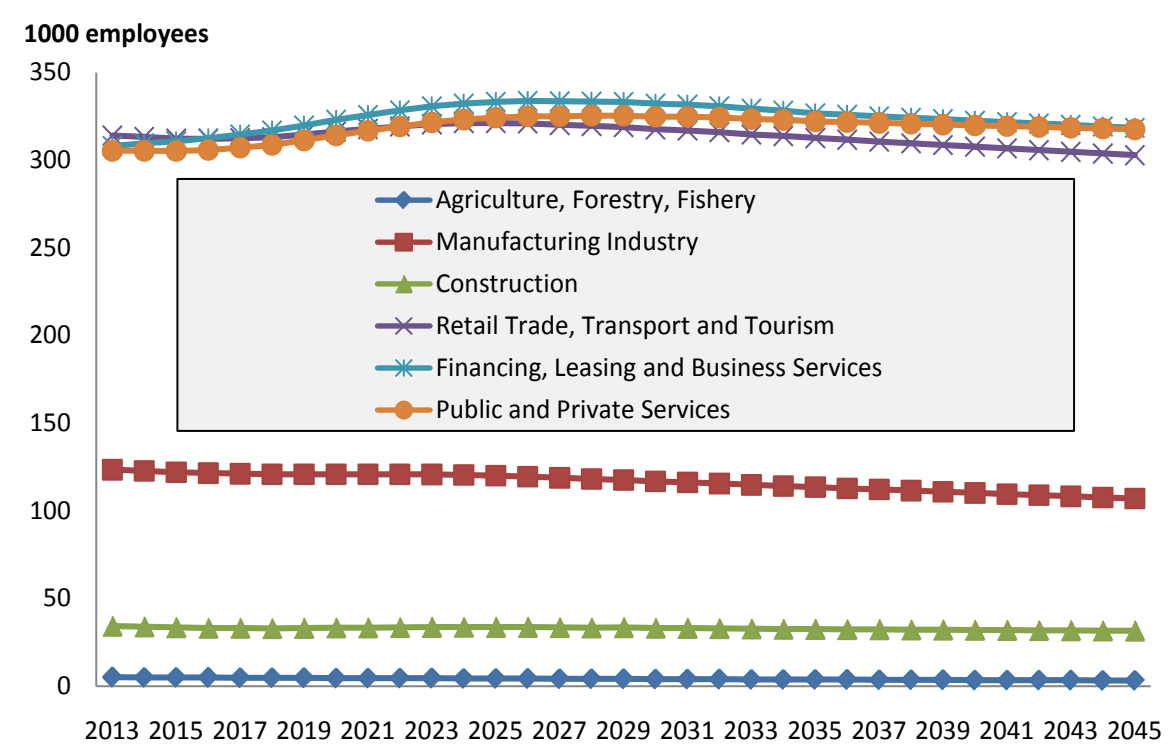

Figure 1. Sectoral forecast of employees in Hamburg. Source: PROGNOS 2010, extrapolation from 2036 to 2045 by Ifo Institute. 
the company database of Hamburg Chamber of Commerce with the water consumption database of Hamburg Water Ltd.

For predicting the industrial and commercial drinking water consumption the gross value added can be used as an indicator as well as the number of employees [14]. In each case, the striking question is whether information about the specific water use per Euro value added or about the specific water use per employee is available. As database is for the calculation of such specific values the Hamburg Chamber of Commerce company database and the Hamburg Water Ltd. water consumption database have been used. With an intersection of both databases it was possible to allocate the different types of points of consumption to the single establishments and to calculate their specific water use for a base year. However, as no information about the value added of the companies and their establishments has been available, but on the number of employees, only the specific water use per employee could be calculated. The results are shown in Table 1.

\section{Forecast of Drinking Water Consumption}

\subsection{Baseline Forecast}

With the results for the economic forecast and the calculation of specific sectoral

Table 1. Specific drinking water demand $\left(\mathrm{m}^{3}\right.$ per employee and year), Employees and total drinking water consumption (in $1000 \mathrm{~m}^{3}$ ) in the base year 2011 .

\begin{tabular}{|c|c|c|c|}
\hline Sector & $\begin{array}{c}\text { Specific } \\
\text { Drinking } \\
\text { Water } \\
\text { Demand } \\
\left(\mathrm{m}^{3} / \text { E } / \text { year }\right)\end{array}$ & Employees & $\begin{array}{c}\text { Total Drinking } \\
\text { Water } \\
\text { Consumption } \\
\left(1000 \mathrm{~m}^{3}\right)\end{array}$ \\
\hline Agriculture, Forestry, Fishery & 69.5 & 5203 & 361.6 \\
\hline Mining and Quarrying & 21.4 & 593 & 12.7 \\
\hline Industry & 22.2 & 119,092 & 2643.9 \\
\hline Energy and Water Supply & 54.3 & 5625 & 305.3 \\
\hline Construction & 5.8 & 35,015 & 202.7 \\
\hline Retail Trade and Maintenance & 19.3 & 171,020 & 3309.2 \\
\hline Tourism & 45.0 & 53,181 & 2393.1 \\
\hline Transport and communications & 9.9 & 95,020 & 938.4 \\
\hline Financial Services and Insurance & 10.7 & 51,682 & 554.1 \\
\hline $\begin{array}{l}\text { Real estate, Rental and } \\
\text { Business Services }\end{array}$ & 23.7 & 255,371 & 6061.4 \\
\hline $\begin{array}{l}\text { Public administration and defense, } \\
\text { Social security }\end{array}$ & 10.5 & 60,144 & 631.5 \\
\hline Education & 2.9 & 59,471 & 174.3 \\
\hline Health and Social Services & 59.5 & 99,932 & 5946.0 \\
\hline Other public and private services & 10.5 & 73,900 & 779.5 \\
\hline Total & & $1,099,923$ & $24,313.5$ \\
\hline
\end{tabular}

Source: Calculations and estimations of the Ifo Institute based on Hamburg Chamber of Commerce, Ham burg Water Ltd. and PROGNOS 2010. 
water use in the base year it was possible to predict the industrial and commercial drinking water consumption by making additional assumptions about the development of the specific water use in the different sectors. The economic forecast was the basis for the prediction of the water consumption which was done by aggregating the data of the Hamburg Chamber of Commerce company database up to the corresponding fourteen branches, by calculating specific water use per employee for each branch and by multiplying the specific values with the predicted employment figures.

The following data were used as a reference point for the water demand forecast of the industrial and commercial sector in Hamburg:

- The company database of the Hamburg Chamber of Commerce with 55,706 registrations,

- The water consumption database of Hamburg Water Ltd. differentiated according to points of consumption,

- The sectoral forecasts of the labor force for Hamburg by 2035 from PROGNOS. This forecast was updated to 2045 and served as the basis for the water demand forecast. The delimitation of sectors was matched with the company database.

By determining the specific water demand for each sector and developing of assumptions about efficiency improvements in drinking water consumption the total industrial and commercial drinking water demand was predicted. The corresponding estimates were secured through written and oral inquiries of major customers of Hamburg Water Ltd. and experts from the water sector. Beside the official data and the forecasts of PROGNOS a special survey of the water consumers from the industrial and commercial sector was carried out to collect additional data and information about the consumption characteristics and about the expected changes in water use in the different sectors. This special survey was conducted in two survey waves in the first quarter of 2013. Additional interviews with major water consuming companies were carried out to get indications how the specific water consumption could develop in the future.

In the water consumption forecast two scenarios were distinguished: A baseline forecast with constant specific water demand in each branch and a reference forecast with divergent development of specific water demand in the different branches. In the baseline forecast an unchanged development of specific water consumption per employee in the individual sectors was assumed. As can be seen in Figure 2, the industrial and commercial demand for water undulates. It initially rises from $24.3 \mathrm{million} \cdot \mathrm{m}^{3}$ in 2011 by $4.8 \%$ to $25.5 \mathrm{million} \cdot \mathrm{m}^{3}$ in 2026 to fall again in the following years until the demand in 2045 finally with 24.4 million $\cdot \mathrm{m}^{3}$ is only by $0.5 \%$ higher than in the base year. The reason for this undulating course lies in the assumptions concerning the development of the workforce.

\subsection{Reference Forecast}

In reality, the development of specific water consumption in the various sectors 


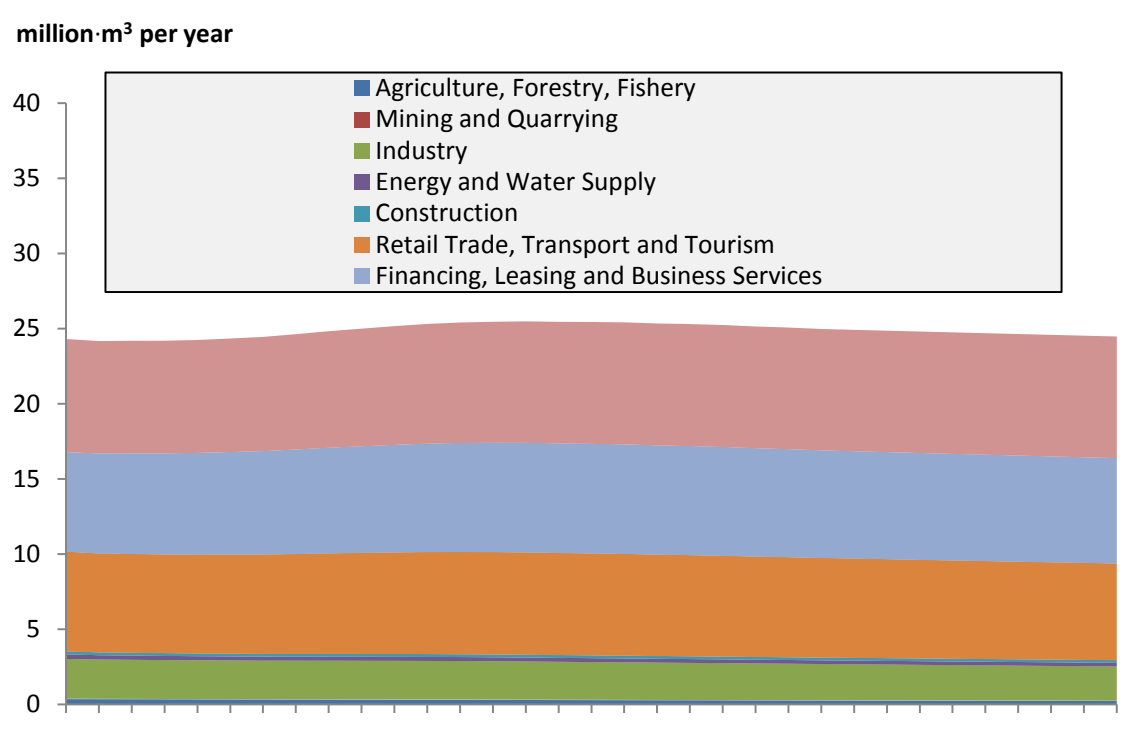

20132015201720192021202320252027202920312033203520372039204120432045

Figure 2. Sectoral baseline forecast of industrial and commercial drinking water consumption in Hamburg. Source: Calculations and estimations of the Ifo institute based on Hamburg chamber of commerce, Hamburg Water Ltd. and PROGNOS 2010.

of the economy will not be the same, as has been assumed for the baseline forecast. The next step was therefore to investigate how different developments in the various sectors could affect the water demand forecast. Therefore it has to be distinguished between industries that use water only for sanitary purposes and cleaning, and other industries that use water for production purposes as a refrigerant or as a resource that goes into the production. In the first case the water requirement is similar to that of households and it is assumed that the future water demand depends on the number of employed persons. In the second case, the water consumption depends on the development of production or provision of services and thus only indirectly on the number of employed persons. However, it should be noted that major water-intensive industrial companies also extract water from their own wells in addition to the public water supply. However, this kind of self-extraction is not part of the drinking water demand forecast.

Which development of the specific water use can be assumed for the individual sectors of the economy in the future? The following arguments are based on plausibility considerations as well as on expert interviews that were conducted with representatives of major customers of Hamburg Water Ltd. Based on these considerations, the following assumptions regarding the future development of specific water consumption (in $\mathrm{m}^{3}$ of drinking water per employee) were made for the 14 industries that are distinguished in the forecast:

\subsubsection{Agriculture, Forestry, Fishery}

In agriculture water is needed to irrigate the plants. It would follow that the more water is required, the more plants are grown. However, it has to be considered that irrigation plays only a minor role in Germany and where necessary, farmers frequently irrigate the fields from their own wells. In addition, agricul- 
ture is not very important in a big city (approximately 5400 workers in Hamburg in 2008). For agriculture in Hamburg, as well for forestry and fisheries, it can therefore be assumed that the demand for drinking water is similar to that in private households and dependent on the development of employment figures.

Assumption: Constancy of the specific water demand.

\subsubsection{Mining and Quarrying}

This sector plays only a marginal role in Hamburg with about 600 workers. For this sector it can be assumed that the use of water for production purposes is covered mainly by self-extraction. The demand for drinking water will therefore depend on the development of employment figures.

Assumption: Constancy of the specific water demand.

\subsubsection{Manufacturing Industry}

In the different industrial branches water is widely used for cooling or as a resource of production. For the purpose of cooling, however, surface water is predominantly used and in the water-intensive industries, where the water is used as a resource, as in the chemical industry or the paper industry, it is often selfextracted. An exception is the food industry. Here the drinking water used for the production of food or drink is taken from the public network, as far as one does not have adequate own wells. Further indications emerge from the written survey: Here the majority of industrial plants reported that the water consumption will develop in the future in proportion to the number of employed persons or to sales. For the manufacturing industry in Hamburg as a whole it therefore can be assumed that the demand for drinking water is approximately proportional to the number of employees and that only small increases in efficiency can be expected.

Assumption: Decrease of the specific water demand by $0.5 \%$ per year.

\subsubsection{Energy and Water Supply}

In the energy supply, water is used primarily for the purpose of cooling. For this purpose, mainly surface water is used and not drinking water. In the water utilities, water is extracted for the drinking water supply of the costumers. The own consumption of drinking water is limited to the sanitary requirements of the workforce.

Assumption: Constancy of the specific water demand.

\subsubsection{Construction}

The water consumption in the construction sector is rather low, and this applies especially for the consumption of drinking water (about $2 \mathrm{~m}^{3}$ per employee per year). Savings are hardly to be expected, therefore, the demand is likely to develop in proportion to the employment figures.

Assumption: Constancy of the specific water demand.

\subsubsection{Retail Trade and Maintenance}

Drinking water is used here only for sanitary and cleaning purposes. Corres- 
ponding to the experts interviews, there is a quite significant potential for the use of water saving technologies in the maintenance sector. Therefore it can be expected that the demand for drinking water will develop at a lower rate than the number of employees.

Assumption: Decrease of the specific water demand by $1.0 \%$ per year.

\subsubsection{Tourism}

According to the Hamburg Chamber of Commerce an increase in overnight stays in tourism can be expected for Hamburg. The water demand will therefore increase more in the tourism and leisure industry than in the private households. Here there is a high demand potential with high growth rates, which is mainly due to the number of tourists, the number of overnight stays and the occupancy of hotel beds. The demand for drinking water is therefore likely to grow disproportionately in relation to the employment figures.

> Assumption: Increase in specific water demand by $1.0 \%$ per year.

\subsubsection{Transport and Communications}

Due to the ports in Hamburg the transport sector plays a much greater role than in the national average. After the results of the interviews in the area of logistics a decline in the specific water consumption can be expected. Also the large transportation companies Lufthansa Technik and Deutsche Bahn expect a constant or decreasing water demand.

Assumption: Decrease of the specific water demand by $1.0 \%$ per year.

\subsubsection{Financial Services and Insurance}

Water consumption in the financial services and insurance sector mainly consists of the sanitary water demand for the employees. The consumption characteristics thus correspond to those of households, with exception of the consumption of water for showers and washing dishes and thus also the corresponding savings cannot be realized. With respect to the use of water-saving faucets still some improvements are to be expected. Therefore it can be assumed that some efficiency gains take place.

$>$ Assumption: Decrease of the specific water demand by $0.5 \%$ per year.

\subsubsection{Real Estate, Rental and Business Services}

In this sector, the same consumption patterns as in the financial services and insurance sector can be assumed. Therefore it can be expected that similar efficiency gains take place.

Assumption: Decrease of the specific water demand by $0.5 \%$ per year.

\subsubsection{Public Administration and Defense, Social Security}

Here the same consumption patterns can be assumed as in both sectors mentioned before. In the area of defense the demand for water for personal hygiene plays a similar role as in the private households, with corresponding saving potentials. Thus, the specific water consumption could slightly stronger decline than in the aforementioned sectors. 
Assumption: Decrease of the specific water demand by $0.75 \%$ per year.

\subsubsection{Education}

Here the demand for water results primarily from the sanitary water demand without further hygiene purposes such as showers. However, the number of employed persons is not only relevant in this sector, but also the number of trainees. As it can be expected that the latter tends to increase, it can be assumed that their demand growth offsets savings in consumption of the employees.

Assumption: Constancy of the specific water demand.

\subsubsection{Health and Social Services}

The demand for water in the social services sector is similar to the demand in the financial services and insurance sector. On the contrary, in the health sector water demand depends more on the number of patients than on the number of employees. Because of these contrasting developments in the health and social services sector, it is assumed that the specific water consumption on average remains constant.

Assumption: Constancy of the specific water demand.

\subsubsection{Other Public and Private Services}

This is a highly heterogeneous sector, which includes in addition to pure office work also the leisure industry and parts of tourism businesses as well as different branches of handiwork, for example cleaners or hairdressers. In this sector, modern water-saving technologies are far from state of the art, resulting in a high potential for their further use. Also for the leisure and tourism industry it can be expected that the water-saving idea will gain ground. Therefore in the future a significant decrease in specific water consumption per employee can be expected for the sector as a whole.

Assumption: Decrease of the specific water demand by $1.5 \%$ per year.

These assumptions lead to the following sectoral developments of the absolute water consumption until the year 2045 (Table 2). In tourism, the total water consumption will increase by $41.5 \%$ until the year 2045 , in the health and social services by $10.5 \%$ and ineducation by $2.2 \%$. These are sectors where high economic growth can be expected. The highest decrease takes place in mining and quarrying $(-56.0 \%)$, followed by agriculture, forestry, fishery $(-37.1 \%)$, other public and private services $(-35.1 \%)$, public administration and defence, social security $(-33.8 \%)$ and retail trade and maintenance $(-33.3 \%)$. In the industrial and commercial sector as a whole the total water consumption will decrease by $7.6 \%$.

\section{Final Results and Concluding Remarks}

The result of the drinking water consumption forecast is that despite an increasing efficiency of water use in most sectors of the Hamburg economy the resulting water savings are largely offset by economic growth, especially in three sectors with high employment figures. By contrast, certain industries as agriculture, 
Table 2. Change of sectoral water consumption in the reference forecast.

\begin{tabular}{|c|c|}
\hline Sector & $\begin{array}{l}\text { Change in total water } \\
\text { Consumption 2013-2045 }\end{array}$ \\
\hline Agriculture, Forestry, Fishery & $-37.1 \%$ \\
\hline Mining and Quarrying & $-56.0 \%$ \\
\hline Industry & $-26.8 \%$ \\
\hline Energy and Water Supply & $-20.4 \%$ \\
\hline Construction & $-9.8 \%$ \\
\hline Retail Trade and Maintenance & $-33.3 \%$ \\
\hline Tourism & $+41.5 \%$ \\
\hline Transport and Communications & $-30.8 \%$ \\
\hline Financial Services and Insurance & $-28.4 \%$ \\
\hline Real Estate, Rental and Business Services & $-8.3 \%$ \\
\hline Public Administration and Defense, Social Security & $-33.8 \%$ \\
\hline Education & $+2.2 \%$ \\
\hline Health and Social Services & $+10.5 \%$ \\
\hline Other public and private services & $-35.2 \%$ \\
\hline Total & $-7.6 \%$ \\
\hline
\end{tabular}

Source: Ifo forecast based on PROGNOS 2010, Hamburg water Ltd., Hamburg chamber of commerce and interviews with experts.

forestry, fishery or energy and water supply have despite their very high specific drinking water needs due to their small share of total employment an almost negligible influence on the demand for drinking water.

In the baseline forecast, total industrial and commercial drinking water consumption in 2045 is only $0.5 \%$ higher than in the base year 2011. In the reference forecast, the drinking water consumption in 2045 is 2 million cubic meters or 8.0\% lower compared with the baseline forecast (Figure 3 ). This difference corresponds to 2 million $\cdot \mathrm{m}^{3}$ of water.

Finally, it should be noted that the forecast of economic development and industry-specific water consumption is associated with significantly more uncertainty than the forecast of demographic trends and the water consumption behavior of private households. Comparable water demand forecasts for other cities or regions treat the industrial water consumption compared to domestic consumption rather rudimentary. Also in those studies, the number of employees is used as a benchmark for the water demand forecast instead of sales or value added. Hence some blurring may arise because the development of the workforce may remain behind the development of value added or turnover due to increases in productivity. This blurring is however relativized insofar as the demand for drinking water in most industries mainly depends on the number of 


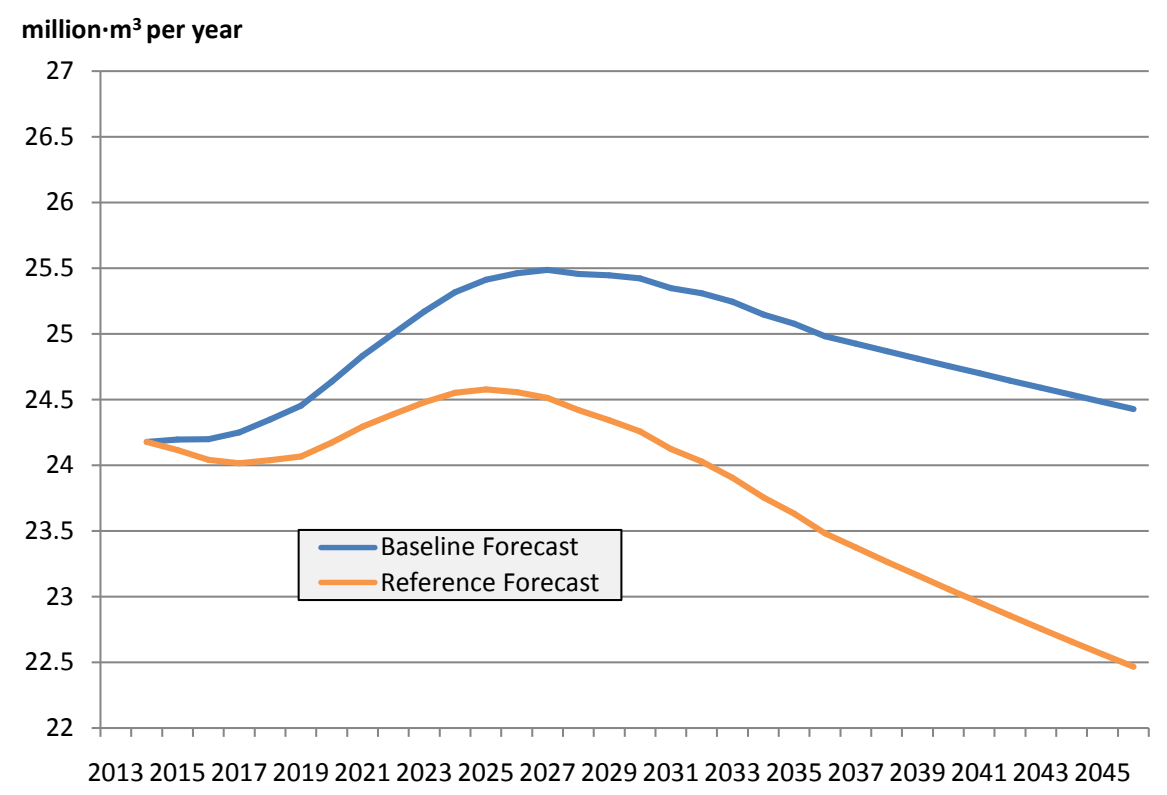

Figure 3. Industrial and commercial drinking water consumption at Hamburg: baseline and reference forecast. Source: Ifo institute based on PROGNOS 2010, Hamburg water Ltd., Handelskammer Hamburg.

employed persons and less on the production volume.

\section{References}

[1] Kluge, T., Liehr, S., Schulz, O., Sunderer, G. and Wackerbauer, J. (2013) Water Demand Forecast 2045 for the Supply Area of Hamburg Water, Institute for Socio-Ecological Research (ISOE) and Ifo Institute, Frankfurt/Main, Munich.

[2] ISOE/COOPERATIVE (2007) Water Demand Forecast 2030 for the Supply Area of the Hamburg Water Utilities Limited in the Metropolitan Region of Hamburg. Institute for Socio-Ecological Research and COOPERATIVE, Frankfurt/Main and Darmstadt.

[3] Grossmann, J. and Hofmann, H. (2008) Integrated Water Demand Forecasting. Part 1: Development of an Innovative Forecast Model for Hamburg Water. GWF Waterl Waste Water, 10, 758-763.

[4] Grossmann, J. and Meinzinger, F. (2016) Update of the Integrated Water Demand Forecast for Hamburg up to the Year 2045. Part 2: Results. GWF Water/ Waste Water, 2, 166-73.

[5] Liehr, S., Schulz, O., Kluge, T., Sunderer, G. and Wackerbauer, J. (2016) Update of the Integrated Water Demand Forecast for Hamburg up to the Year 2045. Part 1: Basics and Methodology. GWF Waterl Waste Water, 2, 156-165.

[6] Constitution of Hamburg (in German) (11th Edition), 6 June 1952, Retrieved 21 September 2008.

[7] http://www.hamburg.de/info/3277402/hamburg-in-zahlen.html

[8] Twenty-Foot Equivalent Unit TEU: Unit of Cargo Capacity Used to Describe the Capacity of Container Ships and Container Terminals, Based on the Volume of a 20-Foot-Long $(6.1 \mathrm{~m})$ Standard-Sized Intermodal Container.

[9] https://en.wikipedia.org/wiki/List_of_busiest_ports_in_Europe

[10] Hamburg Dictionary (1998) Zeise Publisher's Hamburg. 
[11] Hamburg from Altona to Zollenspieker-Handbook for all Districts of the Hanseatic City (2002) Hoffmann and Campe Publisher's Hamburg, 884.

[12] Hamburg Water Annual Report (2011).

[13] PROGNOS (2010) Germany Report 2035, Basel.

[14] Schmidt, H. (2003) Studies on the Development of Drinking Water Consumption and Its Determinants in a Conurbation Area, Berlin.

Submit or recommend next manuscript to OALib Journal and we will provide best service for you:

- Publication frequency: Monthly

- 9 subject areas of science, technology and medicine

- Fair and rigorous peer-review system

- Fast publication process

- Article promotion in various social networking sites (LinkedIn, Facebook, Twitter, etc.)

- Maximum dissemination of your research work

Submit Your Paper Online: Click Here to Submit

Or Contact service@oalib.com 